\title{
Application of PSO for optimal coordination of directional over- current relays in distribution system with distributed renewable energy sources
}

\author{
Lazhar Bougouffa ${ }^{1}$, Abdelaziz Chaghi ${ }^{2}$ \\ ${ }^{1}$ Department of Electrical of Engineering, Faculty of Technology, University of El Oued, El-Oued, Algeria \\ ${ }^{2}$ LSP-IE Research Laboratory, Department of Electrical of Engineering, Faculty of Technology, \\ University of Batna 2, Batna, Algeria
}

\section{Article Info \\ Article history: \\ Received Aug 13, 2020 \\ Revised Feb 12, 2021 \\ Accepted Feb 22, 2021}

\section{Keywords:}

Distributed renewable energy sources

DOCRs

Power system protection PSO

\begin{abstract}
The use of distributed renewable energy sources (D-RES) in the electrical network has expanded greatly. However, integration of these resources into distribution systems caused more problems in protection related issues such as mis-coordination and changes the direction and value of fault currents. When connecting new D-RES to electrical power distribution networks, it is required to re-coordinate directional over-current relays (DOCR) to ensure the continuity of the power transmission when the short circuits take place. This work presented a particle swarm optimization (PSO) algorithm to determine two independent variables called pickup current (Ip) and time dial setting (TDS) for optimal setting of relays. From analysis result, the impacts of RES location in the distribution system on DOCRs had been observed on the optimal relays settings.
\end{abstract}

This is an open access article under the CC BY-SA license.

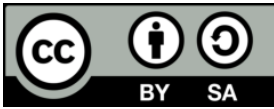

\section{Corresponding Author:}

Lazhar Bougouffa

Department of Electrical of Engineering

University of El Oued

PO BOX 789, 39000, El-Oued, Algeria

Email: bougouffa-lazhar@univ-eloued.dz

\section{INTRODUCTION}

Distributed renewable energy generation is small power-generating unit clubbed with modern technologies and present diverse challenges while integrating with utility grid Most of the distributed renewable energy sources (D-RESs) shall be located near load centre on distribution grid. D-RES introduces negative effects on system operation. One of the negative impacts is relay coordination [1]. The integration of distributed renewable energy sources (D-RES) on the electrical network contains many advantages.

However, the result of introducing these energies in the network will change the value and direction of energy flow as well as short-circuit current levels in different points. Several factors may lead to the effects of RES energies on protection devices, including the type of technology, capacitance, and the position in the network [2].

Bougouffa and Chaghi [3] proposed a dual simplex method to find the setting of time dial setting (TDS) while keeping constant values of Ip in modified IEEE 33-bus with installing the D-RES. In the present article, a particle swarm optimization is proposed to find out the new setting for both TDS and $\mathrm{I}_{\mathrm{P}}$ of relays with respect to various constraints in the presence of two D-RES. 


\section{DIRECTIONAL OVER-CURRENT RELAYS}

For optimal coordination of directional over-current (DOC) relays, it is necessary to determine the optimal values of TDS and IP of each relay in the system, this optimization of TDS and IP for minimize the operating time of the primary relays. The tripping time equation of DOC relay is a non-linear equation, depending on the fault current and both TDS and IP settings. Thus, the relay tripping time equation for DOC relay is given by (1) [4], [5].

$$
T_{o t}=T D S \times \frac{0,14}{\left(\frac{I_{f}}{K C T \times I_{p}}\right)^{0.02}-1}
$$

Where, KCT is the current transformer ratio. The pickup value is the minimum value of the current for which the relay operates. The operating time $\left(\mathrm{T}_{\mathrm{ot}}\right)$ of the relay is defined by the TDS for each current value. The limits on the TDS can be presented as (2).

$$
T D S_{i}^{\min } \leq T D S_{i} \leq T D S_{i}^{\max }
$$

The TDS are assumed to vary between 0.05 and 1.2 .

$$
I_{P i}^{\min } \leq I_{P i} \leq I_{P i}^{\max }
$$

The pickup current setting Ip are assumed to vary between 0.25 and 2.5 with step 0.25 .

When a fault occurs, there must be primary protection for isolat as soon as possible to reduce the isolated area as much as possible, and in the case of primary relay, other relay should be protected as backup protection to assure the requirement of selectivity. In order to satisfy selective requirements, you must add the following limitation [6], [7].

$$
\begin{aligned}
& T_{\text {back-up }}^{F I}-T_{\text {primary }}^{F I} \leq C T I \\
& T_{j}^{F I}-T_{i}^{F I} \leq C T I
\end{aligned}
$$

Where:

$\mathrm{Tj}^{\mathrm{F} 1}$ is the tripping time of $\mathrm{jth}$ backup relay.

$\mathrm{Ti}^{\mathrm{F} 1}$ is the tripping times of ith primary relay.

The CTI is the minimum time gap in operation between the primary and its backup relay, is usually selected between $0.2 \mathrm{~s}$ and $0.5 \mathrm{~s}$ [4], [7], [8]. The CTI is set to a desired value of $0.3 \mathrm{sec}$.

\section{IMPLEMENTATION OF PROPOSED PSO ALGORITHM ON THE COORDINATION PROBLEM}

The particle swarm optimization (PSO), which has gained rapid popularity as an efficient optimization technique, is relatively a recent heuristic introduced by Eberhart and Kennedy [9]. The various steps involved in the implementation of PSO to the DOCRs problem with 64 decisions variables are: Step1. Input the data of 33 IEEE distribution test system for calculate the power flow and current Step2. Define population size (50), no of iteration $(=500)$, assume suitable values of PSO parameters

Step3. Initial searching points and velocities are randomly generated within their limits. Pbest is set to each initial searching point. The best-evaluated values among individual best $\left(\mathrm{P}^{\text {best }}\right)$ are set to global best $\left(g^{\text {best }}\right)$.

Step4. New velocities are calculated using the equation (9).

Step5. Evaluate the fitness values for new searching point. If evaluated values of each agent is better than previous Pbest then set to Pbest. If the best Pbest is better than best gbest then set to gbest.

Step6. If the maximum iteration is reached stop the process otherwise go to step3.

The summation of tripping times of all primary relays is known as objective function (OF). Conventionally, the optimal coordination problem determines two parameters, that is, the pickup current setting $\mathrm{I}_{\mathrm{P}}$ and the time dial setting TDS. The OF is given by (6).

$$
O F=\min \sum_{i=1}^{N} t_{i l}
$$

Where: $\mathrm{OF}$ is the objective function in sec, 
$\mathrm{t}_{\mathrm{il}}$ is the operating time of the ith relay,

$\mathrm{N}$ is the total DOCRs in the system.

The two variables in the objective function are TDS and Ip. By minimizing both the TDS and Ip we can be able to minimize the tripping time of the primary relays and satisfying the CTI.

\subsection{Goal of Study}

This work presented the PSO algorithm to find the optimal CTI of DOC Relays. The proposed algorithm was evaluated using IEEE 33-bus system in presence of two D-RESs. The main contributions of this paper are using the optimization technique to find optimal relay settings, solve the non-linear coordination problem of DOC Relays with the system changed topology.

\section{CASE STUDIES}

In this paper IEEE 33-bus radial distribution feeder is considered to optimal pair of DOC Relays in presence of two emplacements of D-RES. The operating voltage is $12.66 \mathrm{kV}$. DOC Relays are used in the system to protect the feeder in case of three phase faults. The IEEE 33-bus system is presented in Figure 1 [10], [11]. The model is simulated in MATLAB software without and with renewable energy sources to calculate the optimal setting of DOCRs using PSO method under system changes. The program is implemented for two emplacements of renewable energy sources. Three phase faults are generated on each bus.

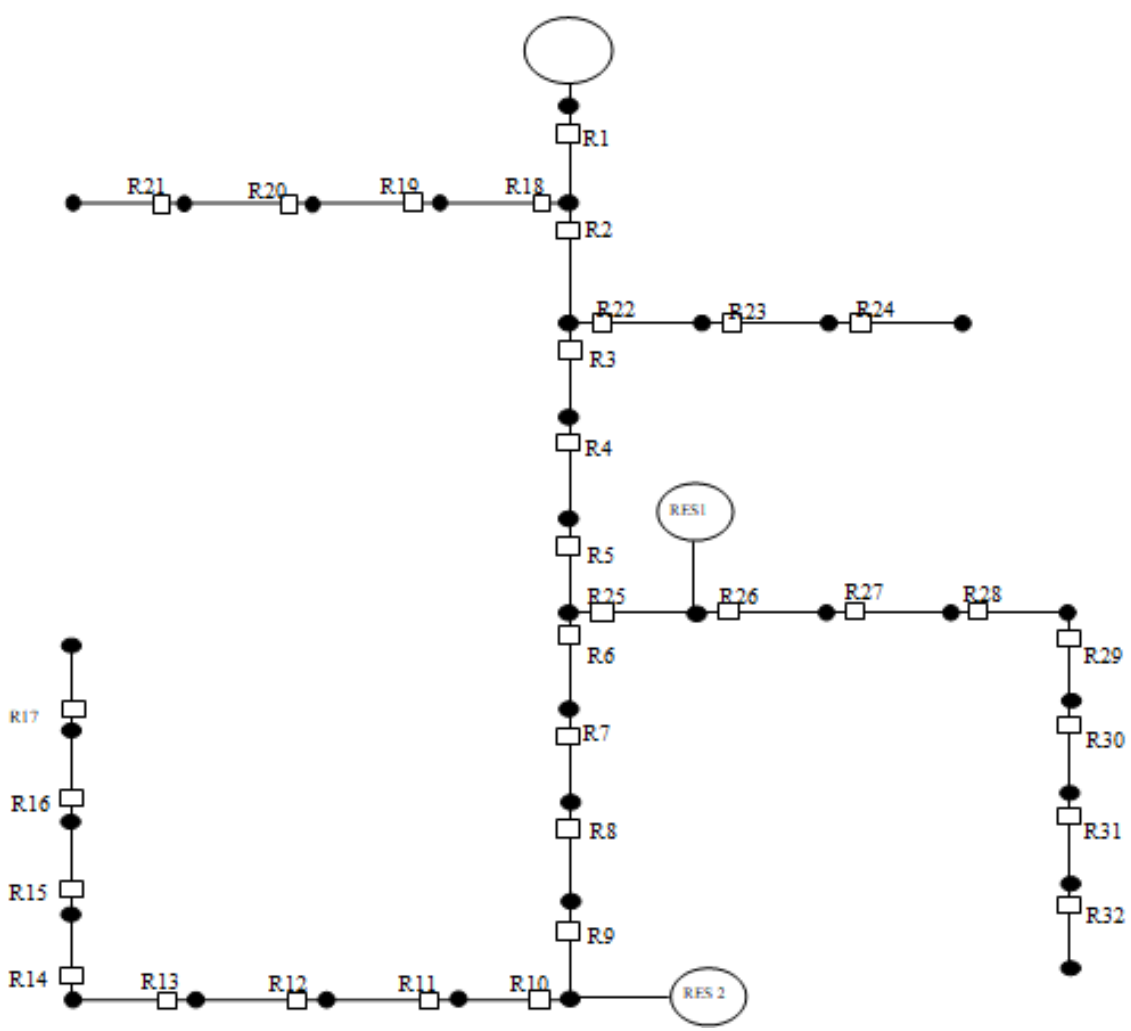

Figure 1. Power distribution system of the IEEE 33-bus system under study

\subsection{Impact of the D-RES on the short circuit level}

From a power perspective, the integration of a new D-RES into the distribution networks will increase the power of the network. Thus, the new source will be modeled in such a way as to take only its current contribution in the event of a short circuit. The electrical network, of which we will determine the different short circuit currents without (and with) D-RES, has a radial architecture Figure 1, and we take a part of this network for the calculations of short circuit currents, as show in Figure 2. 


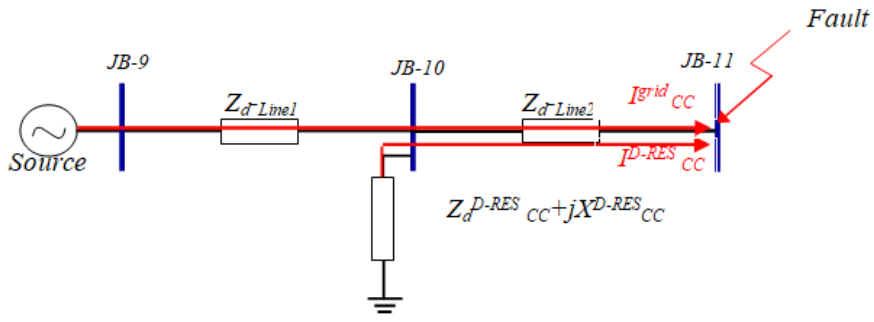

Figure. 2. Simple distribution network with RES

The current in the fault point will be the sum of the short circuit current without D-RES and the short circuit current injected into the network only by the D-RES, is given by (7).

$$
I_{c c}=I_{c c}^{g r i d}+I_{c c}^{D-R E S}
$$

The direct impedance seen between the bar (11) and the earth is (8).

$$
z_{d}^{D-R E S}=z_{d-c c}^{D-R E S}+j X_{c c}^{D-R E S}+Z_{d-\text { Line } 2}
$$

Implies that (9), (10), (11).

$$
\begin{aligned}
& I_{a}^{D-R E S}=\frac{V_{d}^{p}}{Z^{D-R E S}{ }_{d-c c}+j X_{c c}^{D-R E S}+Z_{d-L i n e 2}} \\
& I_{b}^{D-R E S}=a^{2} \cdot \frac{V_{d}^{p}}{Z^{D-R E S}{ }_{d-c c}+j X_{c c}^{D-R E S}+Z_{d-\text { Line } 2}} \\
& I_{c}^{D-R E S}=a \cdot \frac{V_{d}^{p}}{Z^{D-R E S}{ }_{d-c c}+j X_{c c}^{D-R E S}+Z_{d-\text { Line } 2}}
\end{aligned}
$$

We find the fault current is (12), (13), and (14).

$$
\begin{aligned}
I_{a} & =\frac{v_{d}^{P}}{Z_{d-c c}+Z_{d-\text { Line } 1}+Z_{d-\text { Line } 2}}+\frac{V_{d}^{p}}{Z^{D-R E S}{ }_{d-c c}+j X_{c c}^{D-R E S}+Z_{d-\text { Line } 2}} \\
I_{a} & =a^{2} \cdot\left[\frac{V_{d}^{P}}{Z_{d-c c}+Z_{d-\text { Line } 1}+Z_{d-\text { Line } 2}}+\frac{v_{d}^{p}}{Z^{D-R E S}{ }_{d-c c}+j X_{c c}^{D-R E S}+Z_{d-\text { Line } 2}}\right] \\
I_{c} & =a \cdot\left[\frac{V_{d}^{P}}{Z_{d-c c}+Z_{d-\text { Line } 1}+Z_{d-\text { Line } 2}}+\frac{V_{d}^{p}}{Z^{D-R E S}{ }_{d-c c}+j X_{c c}^{D-R E S}+Z_{d-\text { Line } 2}}\right]
\end{aligned}
$$

\begin{tabular}{|c|c|c|}
\hline \multirow[b]{2}{*}{ Relays } & \multicolumn{2}{|c|}{ Setting of TDS } \\
\hline & Without D-RES & With D-RES \\
\hline $\mathrm{TDS}_{1}$ & 0.5000 & 0.5000 \\
\hline $\mathrm{TDS}_{2}$ & 0.3500 & 0.3500 \\
\hline $\mathrm{TDS}_{3}$ & 0.3400 & 0.3400 \\
\hline $\mathrm{TDS}_{4}$ & 0.3300 & 0.3300 \\
\hline $\mathrm{TDS}_{5}$ & 0.3400 & 0.3000 \\
\hline $\mathrm{TDS}_{6}$ & 0.3500 & 0.3500 \\
\hline $\mathrm{TDS}_{7}$ & 0.2700 & 0.2700 \\
\hline $\operatorname{TDS}_{8}$ & 0.2400 & 0.2000 \\
\hline $\mathrm{TDS}_{9}$ & 0.3100 & 0.3800 \\
\hline $\operatorname{TDS}_{10}$ & 0.4600 & 0.5700 \\
\hline $\operatorname{TDS}_{11}$ & 0.4200 & 0.5200 \\
\hline $\operatorname{TDS}_{12}$ & 0.3000 & 0.4000 \\
\hline $\operatorname{TDS}_{13}$ & 0.3400 & 0.4500 \\
\hline
\end{tabular}

\section{RESULTS AND DISCUSSION}

Two locations are chosen for installing the D-RES in the distribution system; to illustrate the effects of D-RES insertions on the setting of Relays. A minimum relay tripping time is the main goal of setting of relays. Also, the CTI is satisfied (i.e., CTI $\geq 0.3$ ). Table 1 shows the optimal results of TDSs in presence of DRES installation in the 33-bus distribution system. Table 2 shows the optimal results of Ips in presence of DRES.

Table 1. Setting values of relais TDS
Table 2. Setting values of relais Ip

\begin{tabular}{ccc}
\hline & \multicolumn{2}{c}{ Setting of Ip } \\
Relays & Without D-RES & With D-RES \\
\hline $\mathrm{Ip}_{1}$ & 0.7300 & 0.7300 \\
$\mathrm{Ip}_{2}$ & 0.7500 & 0.7500 \\
$\mathrm{Ip}_{3}$ & 1.0400 & 1.0400 \\
$\mathrm{Ip}_{4}$ & 0.8100 & 0.8100 \\
$\mathrm{Ip}_{5}$ & 0.3500 & 0.5000 \\
$\mathrm{Ip}_{6}$ & 0.3500 & 0.3500 \\
$\mathrm{Ip}_{7}$ & 1.0700 & 1.0700 \\
$\mathrm{Ip}_{8}$ & 1.0100 & 1.2000 \\
$\mathrm{Ip}_{9}$ & 0.3600 & 0.3600 \\
$\mathrm{Ip}_{10}$ & 0.5200 & 0.5200 \\
$\mathrm{Ip}_{11}$ & 0.5600 & 0.5300 \\
$\mathrm{Ip}$ & 0.5400 & 0.5100 \\
$\mathrm{Ip}_{13}$ & 0.5600 & 0.5500 \\
\hline
\end{tabular}


Table 1. Setting values of relais TDS (continued)

\begin{tabular}{|c|c|c|}
\hline \multirow{2}{*}{ Relays } & \multicolumn{2}{|c|}{ Setting of TDS } \\
\hline & Without D-RES & With D-RES \\
\hline $\operatorname{TDS}_{14}$ & 0.3700 & 0.4100 \\
\hline $\operatorname{TDS}_{15}$ & 0.3600 & 0.4500 \\
\hline $\operatorname{TDS}_{16}$ & 0.3000 & 0.3900 \\
\hline $\operatorname{TDS}_{17}$ & 0.3200 & 0.4500 \\
\hline $\operatorname{TDS}_{18}$ & 0.4000 & 0.0700 \\
\hline $\operatorname{TDS}_{19}$ & 0.2600 & 0.1700 \\
\hline $\operatorname{TDS}_{20}$ & 0.3500 & 0.3700 \\
\hline $\operatorname{TDS}_{21}$ & 0.3200 & 0.3300 \\
\hline $\operatorname{TDS}_{22}$ & 0.3300 & 0.0900 \\
\hline $\operatorname{TDS}_{23}$ & 0.2900 & 0.0500 \\
\hline $\operatorname{TDS}_{24}$ & 0.2800 & 0.3200 \\
\hline $\operatorname{TDS}_{25}$ & 0.4300 & 0.4000 \\
\hline $\operatorname{TDS}_{26}$ & 0.4400 & 0.3800 \\
\hline $\operatorname{TDS}_{27}$ & 0.3200 & 0.2600 \\
\hline $\operatorname{TDS}_{28}$ & 0.3300 & 0.2700 \\
\hline $\operatorname{TDS}_{29}$ & 0.3400 & 0.3700 \\
\hline $\operatorname{TDS}_{30}$ & 0.2600 & 0.2800 \\
\hline $\operatorname{TDS}_{31}$ & 0.3300 & 0.3500 \\
\hline $\mathrm{TDS}_{32}$ & 0.4200 & 0.4400 \\
\hline
\end{tabular}

Table 2. Setting values of relais Ip (continued)

\begin{tabular}{lcr}
\hline \multirow{2}{*}{ Relays } & \multicolumn{2}{c}{ Setting of Ip } \\
& Without D-RES & With D-RES \\
\hline $\mathrm{Ip}_{14}$ & 0.5200 & 1.0500 \\
$\mathrm{Ip}_{15}$ & 0.5300 & 0.5000 \\
$\mathrm{Ip}_{16}$ & 0.5000 & 0.5300 \\
$\mathrm{Ip}_{17}$ & 0.8300 & 0.5300 \\
$\mathrm{Ip}_{18}$ & 1.2200 & 1.2300 \\
$\mathrm{Ip}$ & 1.0300 & 1.0000 \\
$\mathrm{Ip}$ & 0.5000 & 0.5200 \\
$\mathrm{Ip}_{21}$ & 0.5500 & 0.5100 \\
$\mathrm{Ip}$ & 0.9800 & 1.0300 \\
$\mathrm{Ip}$ & 1.0200 & 1.0200 \\
$\mathrm{Ip}_{24}$ & 1.0100 & 0.9800 \\
$\mathrm{Ip}_{25}$ & 0.5200 & 0.7500 \\
$\mathrm{Ip}$ & 0.5200 \\
$\mathrm{Ip}_{27}$ & 0.5500 & 0.5100 \\
$\mathrm{Ip}_{28}$ & 0.5700 & 0.5600 \\
$\mathrm{Ip}_{29}$ & 0.5200 & 0.7400 \\
$\mathrm{Ip}$ & 0.7200 & 1.6000 \\
$\mathrm{Ip}_{31}$ & 1.5600 & 1.1300 \\
$\mathrm{Ip}_{32}$ & 1.0900 & 0.5200 \\
\hline
\end{tabular}

The results obtained after the study from the proposed PSO algorithm of the impact of D-RES on the DOC-Relays settings are displayed in Tables 1 and 2. By examining the results obtained, it can be said that D-RES increased the values of short circuit currents at the fault point. This increase will be reflected in the reduced operating time for protection before damage to the equipment that makes up the electrical network.

\section{CONCLUSION}

In this paper the authors presented the particle swarm optimization method to explain and visualize the influence of D-RES on the protection settings of DOC Relays in the test system. The result of using PSO algorithm on an IEEE 33-bus is compared in two cases with and without D-RES. From analysis result, the impacts of D-RES location in the distribution system had been observed on the optimal relays settings. The results show the optimal settings of DOC-relays for eliminate the three fault currents.

\section{REFERENCES}

[1] A. Shrivastava, D. Kumar Saini, M. Pandit, "Relay co-ordination optimization for integrated solar photo-voltaic power distribution grid," Cogent Engineering, vol. 6, no. 1, pp. 1-19, 2019.

[2] R. M. Chabanloo, H. A. Abyaneh, A. Agheli, H. Rastegar, "Overcurrent relays coordination considering transient behaviour of fault current limiter and distributed generation in distribution power network," IET Generation, Transmission \& Distribution, vol. 5, no. 9, pp. 903-911, 2011.

[3] L. Bougouffa, A. Chaghi, "Effect of renewable energy sources integration on the optimal coordination of directional over-current relays in distribution system," International Journal of Applied Power Engineering IJAPE, vol. 9, no. 3, pp. 250-255, 2020.

[4] P. M. Anderson, "Power System Protection," McGraw-Hill, New York. 1999.

[5] A. S. Noghabi, H. R. Mashhadi, J. Sadeh, "Optimal Coordination of Directional Over-current Relays Considering Different Network Topologies using Interval Linear Programming," IEEE Transactions on Power Delivery, vol. 25. pp. 1348-1354. 2010

[6] Quanming Yue, Feipeng Lu, Weiyong Yu, Jie Wang, "A novel algorithm to determine minimum break point set for optimum cooperation of directional protection relays in multiloop networks," in IEEE Transactions on Power Delivery, vol. 21, no. 3, pp. 1114-1119, July 2006.

[7] T. Amraee, "Coordination of Directional Overcurrent Relays Using Seeker Algorithm," in IEEE Transactions on Power Delivery, vol. 27, no. 3, pp. 1415-1422, July 2012.

[8] Panigrahi B. K, Manohar Singh, A.R. Abhyankar, "Optimal coordination of directional over-current relays using Teaching Learning-Based Optimization (TLBO) algorithm," International Journal of Electrical Power and Energy Systems, vol. 50, pp. 33-41, 2013.

[9] R. Eberhart, J. Kennedy, "Particle Swarm Optimization," in Proceedings of IEEE International Conference on Neural Networks," vol. 4, 1995, pp. 1942-1948.

[10] L. Bougouffa, A. Chaghi, "Optimal Coordination of DOCR for Radial Distribution Systems in Presence of TCSC," International Journal of Power Electronics and Drive System, vol. 7, no. 2, pp. 311-321, 2016.

[11] L. Bougouffa, A. Chaghi, "Dual Simplex Method for Optimal Coordination of DOCR's in Distribution System with D-FACTS," International Journal of Information Science \& Technology, vol. 3, no.3, pp. 3-9. 2019. 